\title{
The Moderating Role of Coping Mechanisms and Being an e-Sport Player Between Psychiatric Symptoms and Gaming Disorder: Online Survey
}

Fanni Bányai ${ }^{1,2}$, MA; Ágnes Zsila ${ }^{3}$, PhD; Gyöngyi Kökönyei ${ }^{1,4,5}$, PhD; Mark D Griffiths ${ }^{6}, \mathrm{PhD}$; Zsolt Demetrovics ${ }^{1,7}$, DSC; Orsolya Király ${ }^{1}, \mathrm{PhD}$

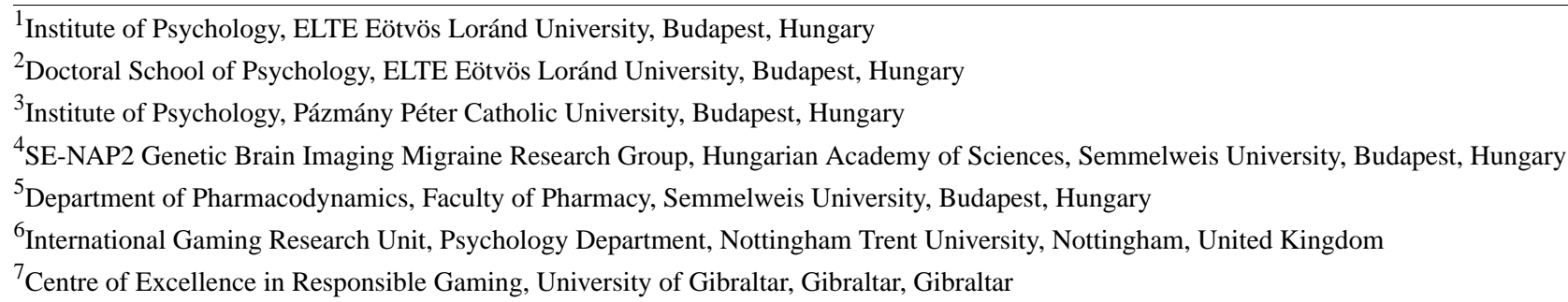

\section{Corresponding Author:}

Zsolt Demetrovics, DSC

Centre of Excellence in Responsible Gaming

University of Gibraltar

Europa Point Campus, Europa Point

Gibraltar, GX111AA

Gibraltar

Phone: 36309761097

Email: zsolt.demetrovics@unigib.edu.gi

\section{Abstract}

Background: The emerging popularity of playing video games (gaming) as a hobby and as a professional sport raises awareness about both the benefits and possible downsides of the activity. Although a healthy and passionate hobby for most, a minority of gamers experience addiction-like symptoms and are considered to have gaming disorder (GD). GD has previously been found to be related to aversive conditions, such as depression or anxiety, as well as putatively maladaptive coping strategies.

Objective: The aim of this study is twofold: to explore the moderating effect of different coping strategies and type of video game usage (professional [e-sport] or recreational) on the relationship between psychiatric symptoms and GD.

Methods: A sample of 3476 gamers ( $n=3133,90.13 \%$ males; mean age 23.20, SD 6.48 years) was recruited via the website and social networking site of the most popular gaming magazine in Hungary (GameStar).

Results: The main effect of psychiatric symptoms was moderate to large in all models, whereas the moderation effects were significant $(P<.001)$ for 4 out of 8 coping strategies (ie, self-blame/self-distraction, denial, emotional/social support, and active coping). However, the explained variance of the models only increased negligibly (from $0.3 \%$ to $0.5 \%$ ) owing to the moderation effect. The direction of the moderations was as expected (ie, putatively maladaptive strategies were associated with more GD symptoms when the level of psychiatric symptoms was high, while putatively adaptive strategies were associated with less). Furthermore, no considerable moderation effect of the player type (recreational vs professional players) was found on the association between psychiatric symptoms and GD ( $\beta=.04 ; P=.02 ; 0.1 \%$ change in the explained variance).

Conclusions: Future studies should be designed to better understand coping-related mechanisms in the context of video gaming and GD.

(JMIR Ment Health 2021;8(3):e21115) doi: 10.2196/21115

\section{KEYWORDS}

gaming disorder; esports; professional gaming; video games; coping skills; psychiatric symptoms; psychiatry; mental health; gaming 


\section{Introduction}

Video game playing (gaming) has become one of the most popular leisure activities globally irrespective of age and gender [1]. Its great popularity has led to the phenomenon of $e$-sports, which refers to professional competitive gaming where teams or individuals compete against each other in a video game [2-5]. There are now organized and sanctioned e-sport competitions worldwide that are hosted by sponsors, featuring live sports commentary. These are watched by large-scale audiences (both at scene and via online streaming platforms such as Twitch.tv, YouTube, etc), and there are big money prizes for the winners [6].

Although the overwhelming majority of gamers globally play in a healthy manner, a small minority experience addiction-like symptoms accompanied by marked psychological distress and significant impairment in personal, family, social, educational, occupational, and/or other important areas of functioning [7]. The severity of the problem is acknowledged by the inclusion of internet gaming disorder (IGD) in Section 3 (Emerging Measures and Models) of the fifth edition of the Diagnostic and Statistical Manual of Mental Disorders in 2013 as a condition warranting further research [8] and by the inclusion of gaming disorder (GD) in the 11th revised edition of the International Classification of Diseases in 2019 as an official diagnosis [9]. Furthermore, there is a wide variety of terms used for problematic or addictive video gaming. This paper uses the term $G D$ given that it is the official term proposed by the World Health Organization.

Similar to substance use or alcohol use disorders, GD has been found to be related to psychiatric symptoms such as depression and anxiety according to numerous epidemiological survey studies [10-12]. One important issue regarding these findings is whether there are factors that moderate these associations. More specifically, the negative effects of emotional or psychiatric distress on an individual's life may depend on the individual's ability to cope with it [13]. Coping can be defined as the cognitive and behavioral responses of individuals in an attempt to manage stressful situations and emotions associated with them [14]. Considering that the context and goals of the individual strongly determine the effectiveness of the strategies $[15,16]$, the adaptive-maladaptive classification could arguably be criticized. However, some strategies may be labeled as putatively maladaptive if they are associated with poor outcomes, especially in the long term. For instance, dispositional rumination - defined as the tendency to dwell on distress-related thoughts passively and repetitively [17] — and avoidance are consistently associated with psychopathology [18]. Similarly, some strategies might be considered as putatively adaptive since they are generally associated with good adjustment. For instance, acceptance of mental experiences is related to better psychological health [19].

Several studies have investigated the association between coping strategies and GD. According to these findings, GD is associated with putatively maladaptive or dysfunctional coping styles [20], such as denial, behavioral disengagement [21], media-related coping, self-distraction, self-blame [22-24], catastrophizing, or rumination [25]. In addition, putatively adaptive coping styles such as active coping, positive reframing, and positive reappraisal have been applied less frequently in the case of gamers at risk of GD or have been negatively related to GD $[22,25]$. Effect sizes range from weak to strong in the case of putatively maladaptive strategies and weak to moderate in the case of putatively adaptive coping styles.

Furthermore, several studies have tested more complex models, in which coping styles have been assumed to mediate between psychiatric symptoms or stress and GD. According to such models, higher rates of stress or specific psychiatric problems such as depression have been associated with or predicted the use of dysfunctional coping styles (eg, avoidance or media-focused coping). This, in turn, has been associated with (or predicted higher rates of) GD or general problematic internet use. Effect sizes for the psychiatric symptoms or coping style associations have been moderate or moderate-to-strong, whereas those for coping style or GD associations have been weak or weak to moderate [26-28].

Although it is plausible to think that increased psychiatric symptoms (eg, depression) may increase the risk of using dysfunctional coping strategies [29], it is also plausible to assume that dispositional coping styles may act as moderators between symptoms and GD. This means that they can influence the association between psychiatric symptoms and GD. It is logical to hypothesize that among individuals who frequently use putatively maladaptive or dysfunctional coping styles when encountering stressful situations in their lives, the relationship between psychiatric symptoms and GD will be stronger than among those who use putatively adaptive coping strategies in general. Findings reporting that escapism (ie, playing videogames to avoid problems and difficulties) is the motive most consistently related to GD [30-32] supports this hypothesis. Therefore, instead of mediation models, this study aims to test whether coping styles (both putatively adaptive and maladaptive) moderate the psychiatric symptoms or GD relationship in the aforementioned way.

The second aim of this study is to test whether player type (recreational vs e-sport players) moderated the association between psychiatric symptoms and GD. The large amount of time and energy that e-sport players spend training to improve their gaming skills and be successful in competitions raises the question of whether e-sport players may be at a higher risk of developing GD than recreational gamers [33]. To date, very few studies have investigated this risk, even though it affects a high number of aspiring e-sport players globally. According to a few previous studies, e-sport players do not report considerably higher GD scores than recreational gamers, and GD-related mechanisms also appear to be similar among e-sport players and highly engaged recreational players [30,31,34]. Therefore, a second assumption was that e-sport players will not significantly differ from highly engaged recreational players in the psychiatric symptoms or GD association. 


\section{Methods}

\section{Participants and Procedure}

Participants were recruited via the website and social networking site (ie, Facebook) of the most popular gaming magazine in Hungary (GameStar). Data were collected using a web-based questionnaire that focused on both healthy and problematic (ie, addictive) use of video games. Participation was voluntary and anonymous. Gamers younger than 18 years (14-17 years of age) were allowed to participate in the survey after providing parental consent to participate. Two shopping vouchers $(60,000$ Hungarian forint, approximately US \$260 each) were used as incentives and raffled among the gamers who participated in the survey. A contact email address was asked by the participants who joined the raffle. The email addresses were used only to inform the winners, and all contacts were deleted afterward.

A total of 7815 participants participated in the survey. According to the aim of this study, participants who provided data for all study-relevant variables (ie, psychiatric symptoms, coping strategies, and symptoms of GD) were included in the data analysis. Consequently, the final sample comprised 3476 gamers ( $n=3133,90.13 \%$ males; mean age 23.20, SD 6.48 years). The study was approved by the Institutional Review Board of the research team's university and was conducted in accordance with the Declaration of Helsinki.

\section{Measures}

\section{Sociodemographic Variables}

Major sociodemographic data were collected, including age, gender, the number of years spent in education and working, and marital status.

\section{Variables Relating to Video Game Use}

Data related to general video game usage were also collected. Participants were asked to report their approximate game time on average hours/weekday and average hours/weekend day. The approximate game time hours/day was calculated as $(5 \times$ week day $+2 \times$ weekend day) $/ 7$. The average gaming time hours/week was calculated as $5 \times$ week day $+2 \times$ weekend day. To identify e-sport gamers and recreational gamers in the sample, participants were asked to indicate the types of competitions (ie, online or offline via local area network competitions) and the frequency of e-sport events they attended in the previous year (response options: "I did not participate in such competitions in the past year"; "1-2 times in the past year"; "3-5 times in the past year"; "6-11 times in the past year"; "several times a month"; and "weekly or more frequently"). Following the classification method of Bányai et al [34] and taking into consideration the theoretical concept $[2,3,6]$ and the methods of how e-sport tournaments are organized, gamers who participated in e-sport tournaments at least 6-11 times in the previous year were defined as "e-sport gamers." Gamers who participated in such tournaments only 5 times or fewer in the previous year were defined as "recreational gamers."

\section{Coping Strategies}

Coping strategies were assessed using the Brief COPE scale [35]. The Brief COPE is a self-report scale assessing 14 different coping strategies (ie, self-distraction, active coping, denial, substance use, use of emotional support, use of instrumental support, behavioral disengagement, venting, positive reframing, planning, humor, acceptance, religion, and self-blame). Each coping strategy is represented by 2 items that are rated on a 4-point Likert scale (ranging from 1="I haven't been doing this at all" to 4="I've been doing this a lot"). Several factors in the Brief COPE scale showed poor internal consistency in this study: self-distraction $(\alpha=.55)$, venting $(\alpha=.58)$, behavioral disengagement $(\alpha=.61)$, acceptance $(\alpha=.66)$, and planning $(\alpha=.69)$. Previous studies, which also found that the original factors of the Brief COPE questionnaire had low internal consistencies, explored alternative factor structures that yielded similar coping strategies but with better psychometric properties [36-38]. Following this conceptual framework, an exploratory factor analysis (EFA) was conducted to find an alternative factor structure for the Brief COPE. A total of 8 factors were identified according to the EFA, including emotional/social support, active coping, self-blame/self-distraction, humor, substance use, denial, religion, and acceptance. According to the aforementioned broad categorization, emotional/social support, active coping, humor, religion, and acceptance were considered to be putatively adaptive coping strategies, whereas self-blame/self-distraction, substance use, and denial were considered to be putatively maladaptive or dysfunctional coping strategies. The newly reconstructed factors showed better internal consistencies ranging between 0.78 and 0.92 , except for the acceptance $(\alpha=.66)$ and self-blame/self-distraction factors $(\alpha=.68)$, which had $\alpha$ values below the .70 threshold (Tables 1 and 2). 
Table 1. Factors obtained using exploratory factor analysis with Promax rotation.

\begin{tabular}{|c|c|c|c|c|c|c|c|c|}
\hline Items of Brief COPE & 1 & 2 & 3 & 4 & 5 & 6 & 7 & 8 \\
\hline $\begin{array}{l}\text { "I've been getting help and advice from other people." (COPE } \\
\text { 10) }\end{array}$ & 0.88 & $-^{\mathrm{a}}$ & - & - & - & - & - & - \\
\hline "I've been getting emotional support from others." (COPE 5) & 0.85 & - & - & - & - & - & - & - \\
\hline $\begin{array}{l}\text { "I've been getting comfort and understanding from someone." } \\
\text { (COPE 15) }\end{array}$ & 0.85 & - & - & - & - & - & - & - \\
\hline $\begin{array}{l}\text { "I've been trying to get advice or help from other people about } \\
\text { what to do." (COPE 23) }\end{array}$ & 0.79 & - & - & - & - & - & - & - \\
\hline $\begin{array}{l}\text { "I've been saying things to let my unpleasant feelings escape." } \\
\text { (COPE 9) }\end{array}$ & 0.63 & - & - & - & - & - & - & - \\
\hline $\begin{array}{l}\text { "I've been taking action to try to make the situation better." } \\
\text { (COPE 7) }\end{array}$ & - & 0.82 & - & - & - & - & - & - \\
\hline $\begin{array}{l}\text { "I've been concentrating my efforts on doing something about } \\
\text { the situation I'm in." (COPE 2) }\end{array}$ & - & 0.82 & - & - & - & - & - & - \\
\hline $\begin{array}{l}\text { "I've been trying to come up with a strategy about what to do." } \\
\text { (COPE 14) }\end{array}$ & - & 0.79 & - & - & - & - & - & - \\
\hline "I've been thinking hard about what steps to take." (COPE 25) & - & 0.69 & - & - & - & - & - & - \\
\hline "I've been criticizing myself." (COPE 13) & - & - & 0.86 & - & - & - & - & - \\
\hline "I've been blaming myself for things that happened." (COPE 26) & - & - & 0.85 & - & - & - & - & - \\
\hline $\begin{array}{l}\text { "I've been turning to work or other activities to take my mind off } \\
\text { things." (COPE 1) }\end{array}$ & - & - & 0.58 & - & - & - & - & - \\
\hline "I've been making fun of the situation." (COPE 28) & - & - & - & 0.96 & - & - & - & - \\
\hline "I've been making jokes about it." (COPE 18) & - & - & - & 0.96 & - & - & - & - \\
\hline $\begin{array}{l}\text { "I've been using alcohol or other drugs to make myself feel bet- } \\
\text { ter." (COPE 4) }\end{array}$ & - & - & - & - & 0.95 & - & - & - \\
\hline $\begin{array}{l}\text { "I've been using alcohol or other drugs to help me get through } \\
\text { it." (COPE 11) }\end{array}$ & - & - & - & - & 0.95 & - & - & - \\
\hline "I've been saying to myself 'this isn't real'." (COPE 3) & - & - & - & - & - & 0.90 & - & - \\
\hline "I've been refusing to believe that it has happened." (COPE 8) & - & - & - & - & - & 0.89 & - & - \\
\hline "I've been praying or meditating." (COPE 27) & - & - & - & - & - & - & 0.90 & - \\
\hline $\begin{array}{l}\text { "I've been trying to find comfort in my religion or spiritual be- } \\
\text { liefs." (COPE 22) }\end{array}$ & - & - & - & - & - & - & 0.90 & - \\
\hline $\begin{array}{l}\text { "I've been accepting the reality of the fact that it has happened." } \\
\text { (COPE 20) }\end{array}$ & - & - & - & - & - & - & - & 0.87 \\
\hline "I've been learning to live with it." (COPE 24) & - & - & - & - & - & - & - & 0.86 \\
\hline
\end{tabular}

${ }^{\mathrm{a}}$ Factor loadings $<0.10$.

Table 2. Factors names and Cronbach alphas obtained using exploratory factor analysis with Promax rotation.

\begin{tabular}{ll}
\hline Factor names & Cronbach alpha \\
\hline Emotional/social support & .86 \\
Active coping & .79 \\
Self-blame/ self-distraction & .68 \\
Humor & .92 \\
Substance use & .92 \\
Denial & .78 \\
Religion & .78 \\
Acceptance & .66 \\
\hline
\end{tabular}




\section{Psychiatric Symptoms}

Psychiatric symptoms were assessed using the Hungarian version of the Brief Symptom Inventory (BSI [39,40]). The scale comprises 53 items on a 5-point Likert scale (from not at all $=0$ to extremely=4), assessing 9 symptoms (ie, somatization, obsession-compulsion, interpersonal sensitivity, depression, anxiety, hostility, phobic anxiety, paranoid ideation, and psychoticism). In this study, 3 subscales of the BSI were used: depression (6 items), anxiety (6 items), and psychoticism (5 items). From the 3 BSI subscales, a summarized index named Psychiatric Symptoms was calculated to determine the intensity of general distress, which showed a strong relationship with GD in previous studies [11,30,31,34]. The Psychiatric Symptoms index with its respective 17 items showed good internal consistency in this study. Cronbach alpha was .93.

\section{Gaming Disorder}

The symptoms of GD were assessed using the Hungarian version of the 10-Item Internet Gaming Disorder Test (IGDT-10 [41]). The IGDT-10 was developed to assess the 9 criteria of IGD as proposed in the DSM-5. Each item of the IGDT-10 assesses 1 DSM-5 criterion, except for the final criterion (eg, "jeopardy or losing a significant relationship, job, or educational or career opportunity because of participation in internet games"), which was operationalized via 2 items to avoid double-barreled questioning. The IGDT-10 has 3 response options (never $=0$, sometimes $=1$, and often=2). To follow the dichotomous structure of the DSM-5, response options were recoded in the following way: never and sometimes options were recoded as no (0), while often responses as yes (1). The ninth and 10th items were recoded into a single item (ie, if any of the 2 original items had an "often" response, the new item was coded as "yes") to resemble the original structure of the IGD. Composite reliability of the IGDT-10 was 0.88. Following the ICD-11 [9] classification of GD, the IGDT-10 scores specified in this study are used as an indicator of GD.

\section{Statistical Analysis}

Data analysis was conducted using SPSS version 22.0 [42] with the PROCESS modeling tool version 2.16.3 [43]. EFA was conducted with principal component analysis with Promax rotation to explore the alternative factor structure of Brief COPE [44]. In the moderation models, the variable of psychiatric symptoms was the independent variable, whereas GD was the outcome variable. Coping strategies and player type (ie, recreational players or professional e-sport players) were the moderators. Player type was coded as $1=$ recreational player and $2=$ professional e-sport player. All variables in the regression models were continuous variables, except for player type. Age and gender were added to the models as covariates. Given the high number of moderation analyses in the case of coping styles, Bonferroni correction was applied. More specifically, the significance level $(P<.05)$ was divided by the number of tests ( $\mathrm{n}=8$ different coping styles). Consequently, a $P$ value of .006 was used as an indicator of statistical significance.

\section{Results}

\section{Descriptive Statistics}

Most of the 3476 gamers in the sample were male $(n=3133$, $90.13 \%$ ), and their ages ranged from 14 to 58 years. The average age was 23.2 (SD 6.48) years. The years they spent in education was approximately 13.2 years (SD 3.04). The findings indicated that $57.33 \%(\mathrm{n}=1993)$ were single, $35.62 \%(\mathrm{n}=1238)$ were in a relationship, $5.78 \%(\mathrm{n}=201)$ were married, $0.48 \%(\mathrm{n}=17)$ were divorced, $0.06 \%(n=2)$ were widowed, and $0.72 \%(n=25)$ did not provide information regarding their marital status. Over half of the gamers in the sample were still studying $(n=1981$, $56.99 \%), 57.31 \%(\mathrm{n}=1992)$ worked part time or full time, and $17.52 \%(n=609)$ of the gamers who were still studying in the educational system also worked. On an average day, the participants played video games for 2.6 (SD 1.31) hours per day and 18.2 (SD 9.20) hours per week. Approximately 1 in 20 gamers $(n=161,4.63 \%)$ identified as e-sport gamers, based on their e-sport tournament participation (ie, they participated in e-sport tournaments at least 6-11 times in the past year).

\section{Factor Analyses}

First, confirmatory factor analysis was conducted on the sample to test the model fit of the 14-factor structure of the Brief COPE scale. The model had an acceptable fit to the data $\left(\chi_{231}^{2}=45551.7 ; \quad P<.001 ; \quad\right.$ comparative fit index 0.963; Tucker-Lewis index 0.947 ; root mean square error of approximation 0.036 [between 0.035 and 0.038]; squared residual 0.03 ). However, many of the originally proposed factors had low internal consistencies, such as self-distraction (0.55), venting (0.58), behavioral disengagement (0.61), acceptance (0.66), and planning (0.69). Owing to this and following the approach of previous studies, an EFA was performed to identify an alternative factor structure of the Brief COPE. Principal component analysis with Promax rotation was performed. The following items had high cross-loadings and were therefore excluded from further analyses: items 6, 12, 16, 17, 19, and 21. A new EFA was then performed using Promax rotation. The Kaiser-Meyer-Olkin (KMO) index was also calculated to measure sample size adequacy. In this sample, EFA produced a good KMO value (0.74) [45]. Bartlett test of sphericity was $\chi_{253}^{2}=31803.7(P<.001)$, indicating that the correlation structure was adequate for factor analyses. On the basis of the scree plot, the proportion of total variance, the eigenvalue-one criterion, and the interpretability of the factors, an eight-factor solution, appeared to best fit the data, accounting for $72.75 \%$ of variance. The results of the EFA analysis are presented in Tables 1-3. 
Table 3. Correlation matrix of the study's variables.

\begin{tabular}{|c|c|c|c|c|c|c|c|c|c|c|}
\hline Variables & $\mathrm{BSI}^{\mathrm{a}}$ & $\mathrm{IGD}^{\mathrm{b}}$ & $\begin{array}{l}\text { Emotional/so- } \\
\text { cial support }\end{array}$ & $\begin{array}{l}\text { Active } \\
\text { coping }\end{array}$ & $\begin{array}{l}\text { Self- } \\
\text { blame/self- } \\
\text { distraction }\end{array}$ & Humor & $\begin{array}{l}\text { Sub- } \\
\text { stance } \\
\text { use }\end{array}$ & Denial & Religion & $\begin{array}{l}\text { Accep- } \\
\text { tance }\end{array}$ \\
\hline \multicolumn{11}{|l|}{ BSI } \\
\hline$r$ & $-^{c}$ & & & & & & & & & \\
\hline$P$ value & - & & & & & & & & & \\
\hline \multicolumn{11}{|l|}{ IGD } \\
\hline$r$ & 0.41 & - & & & & & & & & \\
\hline$P$ value & $<.001$ & - & & & & & & & & \\
\hline \multicolumn{11}{|c|}{ Emotional/social support } \\
\hline$r$ & -0.06 & -0.04 & - & & & & & & & \\
\hline$P$ value & .001 & 0.01 & - & & & & & & & \\
\hline \multicolumn{11}{|c|}{ Active coping } \\
\hline$r$ & -0.18 & -0.14 & 0.39 & - & & & & & & \\
\hline$P$ value & $<.001$ & $<.001$ & $<.001$ & - & & & & & & \\
\hline \multicolumn{11}{|c|}{ Self-blame/self-distraction } \\
\hline$r$ & 0.60 & 0.30 & 0.14 & 0.03 & - & & & & & \\
\hline$P$ value & $<.001$ & $<.001$ & $<.001$ & .06 & - & & & & & \\
\hline \multicolumn{11}{|l|}{ Humor } \\
\hline$r$ & -0.01 & 0.00 & 0.16 & 0.22 & 0.10 & - & & & & \\
\hline$P$ value & .53 & .79 & $<.001$ & $<.001$ & $<.001$ & - & & & & \\
\hline \multicolumn{11}{|c|}{ Substance use } \\
\hline$r$ & 0.22 & 0.10 & 0.10 & -0.01 & 0.24 & 0.12 & - & & & \\
\hline$P$ value & $<.001$ & $<.001$ & $<.001$ & .60 & $<.001$ & $<.001$ & - & & & \\
\hline \multicolumn{11}{|l|}{ Denial } \\
\hline$r$ & 0.41 & 0.24 & 0.12 & 0.00 & 0.40 & 0.06 & 0.18 & - & & \\
\hline$P$ value & $<.001$ & $<.001$ & $<.001$ & .91 & $<.001$ & .001 & $<.001$ & - & & \\
\hline \multicolumn{11}{|l|}{ Religion } \\
\hline$r$ & 0.10 & 0.06 & 0.15 & 0.11 & 0.10 & 0.06 & 0.07 & 0.10 & - & \\
\hline$P$ value & $<.001$ & $<.001$ & $<.001$ & $<.001$ & $<.001$ & .001 & $<.001$ & $<.001$ & - & \\
\hline \multicolumn{11}{|l|}{ Acceptance } \\
\hline$r$ & 0.15 & 0.10 & 0.08 & 0.11 & 0.22 & 0.21 & 0.08 & 0.11 & 0.04 & - \\
\hline$P$ value & $<.001$ & $<.001$ & $<.001$ & $<.001$ & $<.001$ & $<.001$ & $<.001$ & $<.001$ & .03 & - \\
\hline
\end{tabular}

${ }^{\mathrm{a} B S I}$ : Brief Symptom Inventory.

${ }^{\mathrm{b}} \mathrm{IGD}$ : internet gaming disorder.

${ }^{\mathrm{c}}$ Not applicable.

\section{The Moderation Models}

To investigate the moderating effect of coping strategies on the association between psychiatric symptoms and the symptoms of GD, 8 moderation models were tested. The variable of psychiatric symptoms was entered as the independent variable, GD was the outcome variable, and coping strategies were the moderators. Gender and age were treated as control variables and were added to the models as covariates.
The main effect of psychiatric symptoms was moderate to large (ranging from 0.35 to 0.40 ) in all 8 models. The interaction terms (ie, moderation effects) were significant for 4 of the 8 coping strategies. However, these did not increase the explained variance of the models considerably $\left(\mathrm{R}^{2}\right.$ change ranged from 0.003 to 0.005 or $0.3 \%$ to $0.5 \%$ change in the variance; Table 4). More specifically, the moderator effects of self-blame/self-distraction $(\beta=.07 ; P<.001)$ and denial $(\beta=.05$; $P=.001)$ strategies on the association between psychiatric symptoms and the symptoms of GD were significant. When the 
level of psychiatric symptoms was low, the level of GD symptoms was also low, irrespective of the levels of these coping styles. However, when the level of psychiatric symptoms was high, the level of GD symptoms varied based on the level of coping styles the players applied. Those who use self-blame/self-distraction and denial coping styles more experience significantly more GD symptoms than those who use these coping styles less (Figure 1). Moreover, the moderating effect of emotional/social support $(\beta=-.05 ; P=.001)$ and active coping $(\beta=-.06 ; P<.001)$ on the relationship between psychiatric symptoms and GD was also significant. More specifically, when the level of psychiatric symptoms was low, the level of GD symptoms was also low, irrespective of the levels of these coping styles. However, when the level of psychiatric symptoms was high, the level of GD symptoms varied based on the level of coping styles the players applied. Those who use emotional/social support and active coping more experience significantly less GD symptoms than those who use these coping styles more (Figure 1). However, the moderating effect of coping strategies on the association between psychiatric symptoms and symptoms of GD was generally weak in all models. Furthermore, the moderating effects of the other coping strategies, namely acceptance $(\beta=.04 ; P=.02)$, substance use $(\beta=-.04 ; P=.02)$, humor $(\beta=-.02 ; P=.21)$, and religion $(\beta=.00$; $P=.98)$ were not significant after Bonferroni correction was applied (see the Statistical Analysis section). 
Table 4. Moderation analyses of 8 coping styles on the association between psychiatric symptoms and symptoms of gaming disorder.

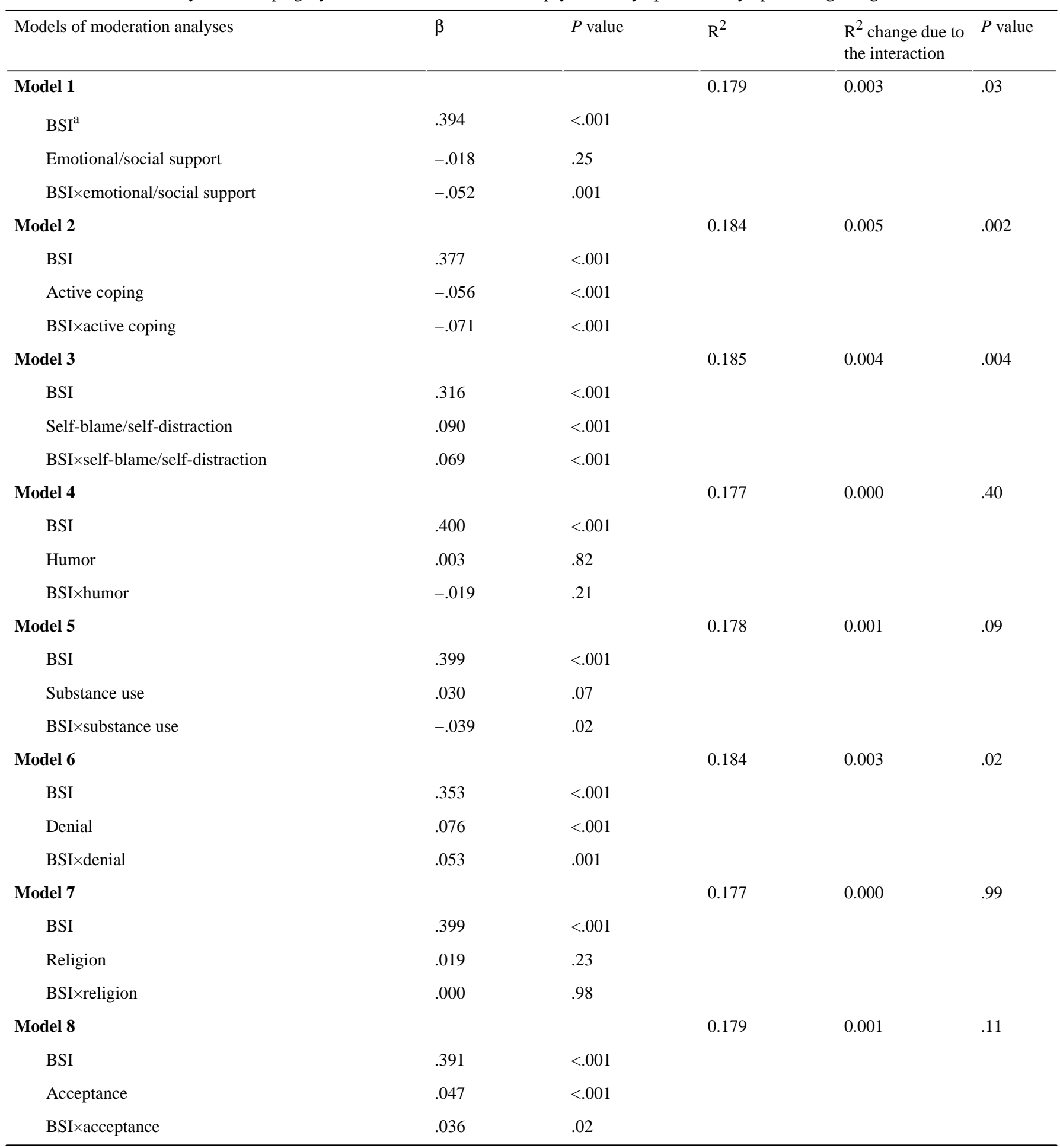

${ }^{\mathrm{a} B S I}$ : Brief Symptom Inventory. 
Figure 1. Two-way interaction effect between coping strategies and psychiatric symptoms on gaming disorder. Brief Symptom Inventory represents the scores of Brief Symptom Inventory of psychiatric symptoms. Gaming disorder represents the scores of the 10-Item Internet Gaming Disorder Test. BSI: Brief Symptom Inventory; IGD: internet gaming disorder.

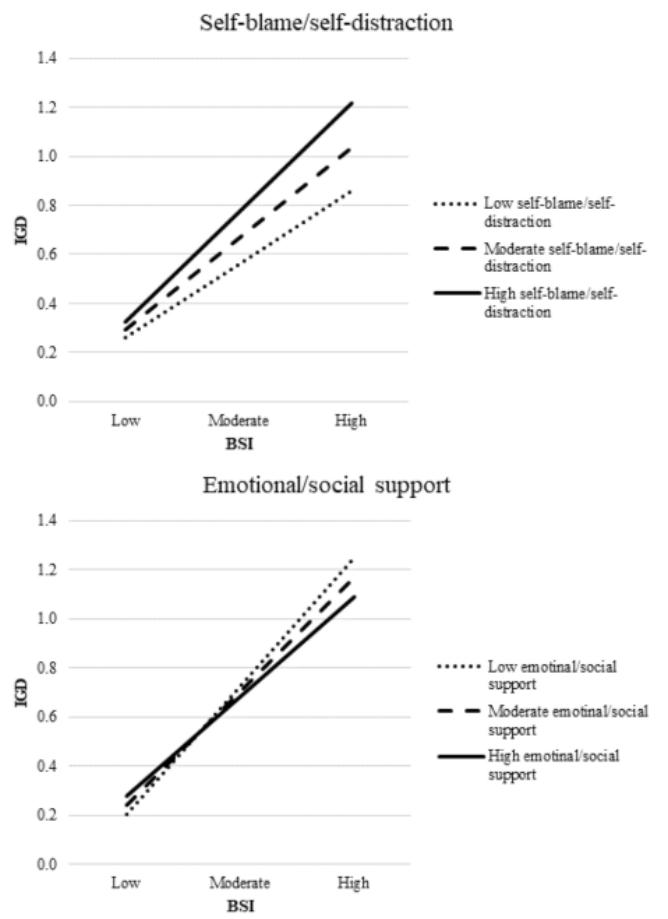

Finally, the moderating role of player type (recreational vs e-sport players) was investigated in the association between psychiatric symptoms and symptoms of GD. The main effect of psychiatric symptoms was also moderate to large $(\beta=.39)$ in this model. Furthermore, although the interaction term was significant $(\beta=.04 ; P=.02)$, the $\mathrm{R}^{2}$ change due to the interaction

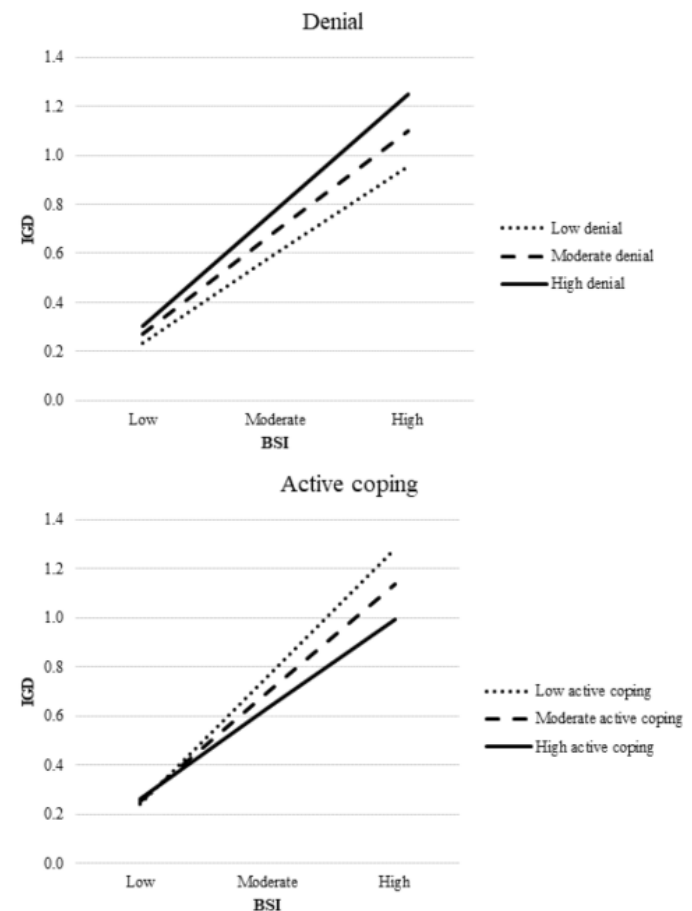

was negligible $(0.001 \%$ or $0.1 \%$ change in the explained variance) and nonsignificant (Table 5). Therefore, the results suggest that e-sport players with more severe psychiatric symptoms are not at a considerably higher risk of encountering symptoms of GD compared to recreational players.

Table 5. Moderation analyses of player style on the association between psychiatric symptoms and symptoms of gaming disorder.

\begin{tabular}{lllll}
\hline Models of moderation analyses & $\beta$ & $P$ value & $\mathrm{R}^{2}$ & $\begin{array}{l}\mathrm{R}^{2} \text { change due to the } P \text { value } \\
\text { interaction }\end{array}$ \\
\hline Model & & & 0.178 & 0.001 \\
$\quad$ BSI & .394 & $<.001$ & \\
e-sport & .035 & .03 & \\
$\quad$ BSIxe-sport & .038 & .02 & \\
\hline
\end{tabular}

${ }^{\mathrm{a}}$ BSI: Brief Symptom Inventory.

\section{Discussion}

This study explored the moderating effect of a wide range of coping strategies and player type (recreational vs e-sport players) on the association between psychiatric symptoms and GD. It was assumed that individuals who frequently used putatively maladaptive or dysfunctional coping styles when encountering stressful situations in their lives would have stronger psychiatric symptoms or GD bonds than those who used putatively adaptive coping strategies in general. In addition, it was assumed that e-sport players would not significantly differ from recreational players in their psychiatric symptoms or GD association. According to the results regarding coping strategies, the main effect of psychiatric symptoms was moderate to large in all models, which is in line with previous research findings [46-50]. The interaction terms (ie, moderation effects) were significant for 4 of the 8 coping strategies (ie, self-blame/self-distraction, denial, emotional/social support, and active coping). However, the explained variance of the models only increased negligibly (from $0.3 \%$ to $0.5 \%$ ). The direction of the moderations was as expected (ie, putatively maladaptive strategies were associated with more GD symptoms when the level of psychiatric symptoms was high, whereas putatively adaptive strategies were associated with less).

However, the negligible effect sizes of these moderations make the results more comparable to those reported by Brand et al [29]. They tested whether dysfunctional coping styles, namely denial, substance use, and disengagement, moderate the 
association between psychopathological aspects (ie, depression and social anxiety) and general internet addiction (including online gaming) but found no considerable moderation effect. In contrast, they found that dysfunctional coping styles mediated between psychopathological aspects and general internet addiction. According to their explanation, higher symptoms of depression and social anxiety can increase the risk of dysfunctional coping strategies, which is associated with higher internet addiction rates. Similarly, many other studies have reported that specific coping styles (eg, avoidance, media-focused coping) mediate between psychiatric symptoms or stress and GD. Given that specific coping styles (especially putatively maladaptive ones as aforementioned) are associated with psychiatric symptoms at moderate or moderate-to-strong levels and with GD at weak or weak-to-moderate levels [26-28] (and in this study; Table 1), it was expected that they would have a mediating effect. A mediating effect suggests that when experiencing high levels of psychiatric symptoms, individuals are more likely to use specific putatively maladaptive coping styles. For instance, in a naturalistic study, a high level of depressive symptoms was associated with an increased use of experiential avoidance on a daily basis [51].

Nevertheless, as mentioned in the Introduction, it is also plausible to think that individuals who frequently (ie, habitually) use putatively maladaptive or dysfunctional coping styles when encountering stressful situations in their lives have stronger psychiatric symptoms or GD bonds than those who use putatively adaptive coping strategies in general. However, it has also been suggested that in concrete situations, numerous factors influence the coping or emotion regulation strategy selection applied by an individual [52]. This would explain why no considerable moderation effects were found even if coping strategies were dispositional or trait-like to a certain degree. Overall, additional studies are necessary to confirm these findings, and longitudinal studies and experiments should be designed to explore the causal relationships in the etiology of GD and to better understand these crucial coping-related mechanisms.

Finally, the assumption regarding the effect of player type (recreational vs e-sport players) on the association between psychiatric symptoms and GD was met because the change in explained variance of the moderation model was negligible $(0.1 \%)$. To date, very few empirical studies have investigated whether e-sport players are at a higher risk of developing GD than recreational gamers. Studies that compared e-sport players and recreational players found significant differences in motivation $[34,53]$ but reported no significant differences in GD and GD-related mechanisms (eg, the mediation effect of gaming motives between psychiatric symptoms and GD; Bányai et al [34]). This is also in line with findings suggesting that increased time spent gaming is not associated with psychiatric problems and is not a good predictor of GD [54]. These results suggest that e-sport players are not necessarily at a higher risk of developing GD than those who are highly engaged recreational gamers. This is also plausible, knowing how goal-oriented and structured e-sport training is [6]. Players have a tight daily schedule, including proper time for eating healthily, sleeping properly, and performing physical exercise. Moreover, they often train in teams and cultivate social bonds while playing as well. Nevertheless, it is important to conduct more research in this field of e-sports and to investigate the risk of GD among e-sport players $[33,55]$.

This study has several limitations that should be noted when interpreting the findings. Although the sample of this study was large, because of its self-selected nature, the results should be generalized with caution. Furthermore, biases of self-report surveys (eg, memory recall and social desirability) should also be considered when interpreting the results. The categorization of e-sports and recreational gamers was based on the number of self-reported gaming competitions they engaged in (ie, frequency of e-sport competitions). Future studies should use more standardized methods for this categorization. Coping strategies were assessed generally and did not consider how individuals cope with different types of stressors. However, it is worth noting that habitually used maladaptive emotion regulation strategies are associated with increased negative affect and atypical cortisol responses to psychosocial stressors in laboratory studies [56]. This suggests that the frequent use of these strategies in different situations may create a vulnerability to mental health problems. Finally, due to the cross-sectional design of the study, causal explanations could not be drawn. Longitudinal and experimental studies should be conducted to address this limitation.

Despite these limitations, this study investigated important questions using a large sample of highly engaged video game players and a subsample of e-sport players. The relationship between psychiatric symptoms and GD has been consistently confirmed. Therefore, understanding factors that attenuate or aggravate this relationship will help in planning better intervention programs. Strategies individuals routinely use to cope with stress and regulate their negative affect can be considered when considering these factors. Understanding why a given individual uses specific affect regulation strategies in a given situation or across situations and the emotional or behavioral consequences of the ways of affect regulation [57] could be an essential component of personalized treatments targeting mental health problems including GD. Furthermore, in relation to prevention and intervention programs, experts should focus on both the coping strategies of the individuals and their style of video game usage. Playing video games can be viewed as a coping strategy. As a media-focused coping style, video game playing could have similar outcomes as self-distraction and behavioral disengagement among some problematic gamers or players diagnosed with GD [22,58,59] when playing games to avoid aversive and stressful situations [60]. Gaming is a recreational activity that primarily serves pleasure, relaxation, and/or stress-relief. However, gamers can also avoid discomfort and escape from their problems in real life. In this regard, future research should focus on the style of video game playing and how this activity is integrated into gamers' lives (eg, recreation, e-sport or problematic gaming, or an escape option from reality). Individual coping styles and emotion regulation strategies also play a role in this and therefore should be considered in the prevention and treatment processes. 


\section{Acknowledgments}

This study was supported by the Hungarian National Research, Development and Innovation Office (KKP126835; ELTE Thematic Excellence Programme 2020, KP2020-IKA-05). OK was supported by the János Bolyai Research Scholarship of the Hungarian Academy of Sciences and by the ÚNKP-20-5 New National Excellence Program of the Ministry for Innovation and Technology from the source of the National Research, Development and Innovation Fund. ÁZ was supported by the ÚNKP-20-4-II New National Excellence Program of the Ministry for Innovation and Technology from the source of the National Research, Development and Innovation Fund. The preparation of this paper for GK was supported by the Hungarian National Research, Development and Innovation Office (Grant No. FK128614) and by the MTA-SE-NAP B Genetic Brain Imaging Migraine Research Group, Hungarian Academy of Sciences, Semmelweis University (Grant No. KTIA_NAP_13-2-2015-0001), Hungarian Brain Research Program (Grant No. 2017-1.2.1-NKP-2017-00002), and ITM/NKFIH Thematic Excellence Programme, Semmelweis University; by the SE-Neurology FIKP grant of EMMI. The funding institutions had no role in the study design, data collection, analysis and interpretation of the data, writing of the paper, or the decision to submit the paper for publication.

\section{Conflicts of Interest}

Eötvös Loránd University (ELTE) receives funding from Szerencsejáték Ltd to maintain a telephone helpline service for problematic gambling. ZD has also been involved in research on responsible gambling funded by Szerencsejáték and the Gambling Supervision Board and provided educational materials for the Szerencsejáték's responsible gambling program. The University of Gibraltar receives funding from the Gibraltar Gambling Care Foundation. However, the funding is not related to this study, and the funding institution had no role in the study design or the collection, analysis, and interpretation of the data, writing the manuscript, or the decision to submit the paper for publication.

\section{References}

1. Essential facts about the computer and video game industry. Entertainment Software Association. 2019 Jun 26. URL: https:/ /www.theesa.com/wp-content/uploads/2019/05/ESA Essential facts 2019 final.pdf [accessed 2020-05-27]

2. Wagner M, editor. On the scientific relevance of esports. 2006 Jun 26 Presented at: International Conference on Internet Computing \& Conference on Computer Games Development, ICOMP; June; Las Vegas, Nevada, USA; 2006; Las Vegas, Nevada, USA.

3. Hemphill D. Cybersport. Journal of the Philosophy of Sport 2005 Jan 01;32(2):195-207. [doi: $10.1080 / 00948705.2005 .9714682]$

4. Adamus T. Playing computer games as electronic sport: In search of a theoretical framework for a new research field. In: Fromme J, Unger A. editors. Computer games and new media multures: A handbook of digital games studies. Dordrechtpringer; 2012:A-90.

5. Jonasson K, Thiborg J. Electronic sport and its impact on future sport. Sport in Society 2010 Feb 12;13(2):287-299. [doi: $10.1080 / 17430430903522996]$

6. Taylor T. Raising the stakessports and the professionalization of computer gaming. Cambridge: MIT Press; 2012:E.

7. Rumpf H, Achab S, Billieux J, Bowden-Jones H, Carragher N, Demetrovics Z. Including gaming disorder in the ICD-11: The need to do so from a clinical and public health perspective: Commentary on: A weak scientific basis for gaming disorder: Let us err on the side of caution (van Rooij. , 2018). Journal of Behavioral Addictions 2018;7(3):A. [doi:

10.31234/osf.io/kc7r9]

8. American PA. Diagnostic and statistical manual of mental disorders. fifth ed. Arlington, VA: American Psychiatric Association; 2013:A.

9. ICD-11 for Mortality and Morbidity Statistics. World Health Organization. 2019 May 27. URL: https://icd.who.int/browse11/ $\underline{1-m / e n}$ [accessed 2020-05-27]

10. Jeong H, Yim HW, Lee S, Lee HK, Potenza MN, Jo S, et al. Reciprocal relationship between depression and Internet gaming disorder in children: A 12-month follow-up of the iCURE study using cross-lagged path analysis. J Behav Addict 2019 Dec 31;8(4):725-732. [doi: 10.1556/2006.8.2019.74]

11. Király O, Bőthe B, Ramos-Diaz J, Rahimi-Movaghar A, Lukavska K, Hrabec O, et al. Ten-Item Internet Gaming Disorder Test (IGDT-10): Measurement invariance and cross-cultural validation across seven language-based samples. Psychology of Addictive Behaviors 2019 Feb;33(1):91-103. [doi: 10.1037/adb0000433]

12. Müller KW, Beutel ME, Dreier M, Wölfling K. A clinical evaluation of the DSM-5 criteria for Internet Gaming Disorder and a pilot study on their applicability to further Internet-related disorders. J Behav Addict 2019 Jan 20;8(1):16-24. [doi: $\underline{10.1556 / 2006.7 .2018 .140]}$

13. Vitaliano PP, DeWolfe DJ, Maiuro RD, Russo J, Katon W. Appraised changeability of a stressor as a modifier of the relationship between coping and depression: A test of the hypothesis of fit. Journal of Personality and Social Psychology 1990;59(3):582-592. [doi: 10.1037/0022-3514.59.3.582]

14. Lazarus R, Folkman S. Stress, appraisal, and copingpringer publishing company; 1984. ISBN 1984 Mar 15:0826141927. [doi: $10.4135 / 9781412952576 . n 198]$ 
15. Cheng C. Assessing coping flexibility in real-life and laboratory settings: A multimethod approach. Journal of Personality and Social Psychology 2001;80(5):814-833. [doi: 10.1037/0022-3514.80.5.814]

16. Troy AS, Shallcross AJ, Mauss IB. A Person-by-Situation Approach to Emotion Regulation. Psychol Sci 2013 Oct 21;24(12):2505-2514. [doi: 10.1177/0956797613496434]

17. Nolen-Hoeksema S, Wisco BE, Lyubomirsky S. Rethinking Rumination. Perspect Psychol Sci 2008 Sep;3(5):400-424. [doi: 10.1111/j.1745-6924.2008.00088.x]

18. Aldao A, Nolen-Hoeksema S, Schweizer S. Emotion-regulation strategies across psychopathology: A meta-analytic review. Clinical Psychology Review 2010 Mar;30(2):217-237. [doi: 10.1016/j.cpr.2009.11.004]

19. Baer RA, Smith GT, Allen KB. Assessment of Mindfulness by Self-Report. Assessment 2016 Jul 26;11(3):191-206. [doi: 10.1177/1073191104268029]

20. Paulus FW, Ohmann S, von Gontard A, Popow C. Internet gaming disorder in children and adolescents: a systematic review. Dev Med Child Neurol 2018 Apr 06;60(7):645-659. [doi: 10.1111/dmcn.13754]

21. Schneider LA, King DL, Delfabbro PH. Maladaptive Coping Styles in Adolescents with Internet Gaming Disorder Symptoms. Int J Ment Health Addiction 2017 Apr 20;16(4):905-916. [doi: 10.1007/s11469-017-9756-9]

22. Dreier M, Wölfling K, Duven E, Giralt S, Beutel M, Müller K. Free-to-play: About addicted Whales, at risk Dolphins and healthy Minnows. Monetarization design and Internet Gaming Disorder. Addictive Behaviors 2017 Jan;64:328-333. [doi: 10.1016/j.addbeh.2016.03.008]

23. Milani L, La Torre G, Fiore M, Grumi S, Gentile DA, Ferrante M, et al. Internet Gaming Addiction in Adolescence: Risk Factors and Maladjustment Correlates. Int J Ment Health Addiction 2017 Mar 20;16(4):888-904. [doi: $10.1007 / \mathrm{s} 11469-017-9750-2]$

24. Rosenkranz T, Müller KW, Dreier M, Beutel ME, Wölfling K. Addictive Potential of Internet Applications and Differential Correlates of Problematic Use in Internet Gamers versus Generalized Internet Users in a Representative Sample of Adolescents. Eur Addict Res 2017 Jun 16;23(3):148-156. [doi: 10.1159/000475984]

25. Kökönyei G, Kocsel N, Király O, Griffiths MD, Galambos A, Magi A, et al. The Role of Cognitive Emotion Regulation Strategies in Problem Gaming Among Adolescents: A Nationally Representative Survey Study. Front. Psychiatry 2019 Apr 29;10. [doi: 10.3389/fpsyt.2019.00273]

26. Kuss D, Dunn T, Wölfling K, Müller K, Hedzelek M, Marcinkowski J. Excessive Internet use and psychopathology: The role of coping. Clinical Neuropsychiatry: Journal of Treatment Evaluation 2017;14(1):73-81.

27. McNicol ML, Thorsteinsson EB. Internet Addiction, Psychological Distress, and Coping Responses Among Adolescents and Adults. Cyberpsychology, Behavior, and Social Networking 2017 May;20(5):296-304. [doi: 10.1089/cyber.2016.0669]

28. Li H, Zou Y, Wang J, Yang X. Role of Stressful Life Events, Avoidant Coping Styles, and Neuroticism in Online Game Addiction among College Students: A Moderated Mediation Model. Front. Psychol 2016 Nov 22;7. [doi: 10.3389/fpsyg.2016.01794]

29. Brand M, Laier C, Young KS. Internet addiction: coping styles, expectancies, and treatment implications. Front. Psychol 2014 Nov 11;5. [doi: 10.3389/fpsyg.2014.01256]

30. Ballabio M, Griffiths MD, Urbán R, Quartiroli A, Demetrovics Z, Király O. Do gaming motives mediate between psychiatric symptoms and problematic gaming? An empirical survey study. Addiction Research \& Theory 2017 Mar 27;25(5):397-408. [doi: 10.1080/16066359.2017.1305360]

31. Király O, Urbán R, Griffiths MD, Ágoston C, Nagygyörgy K, Kökönyei G, et al. The Mediating Effect of Gaming Motivation Between Psychiatric Symptoms and Problematic Online Gaming: An Online Survey. J Med Internet Res 2015 Apr 07;17(4):e88. [doi: 10.2196/jmir.3515]

32. Wai YT, Reer F, Thorsten Q. The interplay of gaming disorder, gaming motivations, and the dark triad. Journal of Behavioral Addictions 2020 Jun 01:2020-2026. [doi: 10.1556/2006.2020.00013]

33. Chung T, Sum S, Chan M, Lai E, Cheng N. Will esports result in a higher prevalence of problematic gaming? A review of the global situation. Journal of Behavioral Addictions. 2019 Sep 01. URL: https://doi.org/10.1556/2006.8.2019.46 [accessed 2020-05-27]

34. Bányai F, Griffiths MD, Demetrovics Z, Király O. The mediating effect of motivations between psychiatric distress and gaming disorder among esport gamers and recreational gamers. Comprehensive Psychiatry 2019 Oct;94:152117. [doi: 10.1016/j.comppsych.2019.152117]

35. Carver CS. You want to measure coping but your protocol' too long: Consider the brief cope. Int. J. Behav. Med 1997 Mar;4(1):92-100. [doi: 10.1207/s15327558ijbm0401 6]

36. Baumstarck K, Alessandrini M, Hamidou Z, Auquier P, Leroy T, Boyer L. Assessment of coping: a new french four-factor structure of the brief COPE inventory. Health Qual Life Outcomes 2017 Jan 11;15(1). [doi: 10.1186/s12955-016-0581-9]

37. Brasileiro SV, Orsini MRCA, Cavalcante JA, Bartholomeu D, Montiel JM, Costa PSS, et al. Controversies Regarding the Psychometric Properties of the Brief COPE: The Case of the Brazilian-Portuguese Version "COPE Breve". PLoS ONE 2016 Mar 23;11(3):e0152233. [doi: 10.1371/journal.pone.0152233]

38. Nahlen Bose C, Bjorling G, Elfstrom ML, Persson H, Saboonchi F. Assessment of Coping Strategies and Their Associations With Health Related Quality of Life in Patients With Chronic Heart Failure: the Brief COPE Restructured. Cardiol Res 2015 Apr;6(2):239-248. [doi: 10.14740/cr385w] 
39. Derogatis L, Spencer P. BSI administrationprocedures manual I. Baltimore, MD: Clinical Psychometric Research; 1975.

40. Urbán R, Kun B, Farkas J, Paksi B, Kökönyei G, Unoka Z, et al. Bifactor structural model of symptom checklists: SCL-90-R and Brief Symptom Inventory (BSI) in a non-clinical community sample. Psychiatry Research 2014 Apr;216(1):146-154. [doi: 10.1016/j.psychres.2014.01.027]

41. Király O, Sleczka P, Pontes HM, Urbán R, Griffiths MD, Demetrovics Z. Validation of the Ten-Item Internet Gaming Disorder Test (IGDT-10) and evaluation of the nine DSM-5 Internet Gaming Disorder criteria. Addictive Behaviors 2017 Jan;64:253-260. [doi: 10.1016/j.addbeh.2015.11.005]

42. IBM SPSS Statistics for Windows, Version 22. Armonk, NY: IBM Corp; 2013.

43. Hayes A. Introduction to mediation, moderation, and conditional process analysis: A regression-based approach. New York: Guilford Publications; 2017:A.

44. Watson B. Making sense of factor analysis: The use of factory analysis for instrument development in health care research. Nurse Researcher 2004;11(3):91-93.

45. Hutcheson G, Sofroniou N. Introductory statistics using generalized linear models. The Multivariate Social Scientist, London/Thousand Oaks/New Dehli: Londonage Publications Ltd; 1999:0761952012.

46. Vadlin S, Åslund C, Hellström C, Nilsson KW. Associations between problematic gaming and psychiatric symptoms among adolescents in two samples. Addictive Behaviors 2016 Oct;61:8-15. [doi: 10.1016/j.addbeh.2016.05.001]

47. Kitazawa M, Yoshimura M, Murata M, Sato-Fujimoto Y, Hitokoto H, Mimura M, et al. Associations between problematic Internet use and psychiatric symptoms among university students in Japan. Psychiatry Clin. Neurosci 2018 May 09;72(7):531-539. [doi: 10.1111/pcn.12662]

48. Kircaburun K, Demetrovics Z, Griffiths MD, Király O, Kun B, Tosuntaş Ş. Trait Emotional Intelligence and Internet Gaming Disorder Among Gamers: The Mediating Role of Online Gaming Motives and Moderating Role of Age Groups. Int J Ment Health Addiction 2019 Dec 03;18(5):1446-1457. [doi: 10.1007/s11469-019-00179-x]

49. Starcevic V, Khazaal Y. Relationships between Behavioural Addictions and Psychiatric Disorders: What Is Known and What Is Yet to Be Learned? Front. Psychiatry 2017 Apr 07;8. [doi: 10.3389/fpsyt.2017.00053]

50. King DL, Delfabbro PH, Perales JC, Deleuze J, Király O, Krossbakken E, et al. Maladaptive player-game relationships in problematic gaming and gaming disorder: A systematic review. Clinical Psychology Review 2019 Nov;73:101777. [doi: 10.1016/j.cpr.2019.101777]

51. Shahar B, Herr NR. Depressive symptoms predict inflexibly high levels of experiential avoidance in response to daily negative affect: A daily diary study. Behaviour Research and Therapy 2011 Oct;49(10):676-681. [doi:

10.1016/j.brat.2011.07.006]

52. English T, Lee IA, John OP, Gross JJ. Emotion regulation strategy selection in daily life: The role of social context and goals. Motiv Emot 2016 Dec 8;41(2):230-242. [doi: 10.1007/s11031-016-9597-z]

53. Martončik M. e-Sports: Playing just for fun or playing to satisfy life goals? Computers in Human Behavior 2015 Jul;48:208-211. [doi: 10.1016/j.chb.2015.01.056]

54. Király O, Tóth D, Urbán R, Demetrovics Z, Maraz A. Intense video gaming is not essentially problematic. Psychology of Addictive Behaviors 2017 Nov;31(7):807-817. [doi: 10.1037/adb0000316]

55. Bányai F, Griffiths M, Király O, Demetrovics Z. The psychology of esports: A systematic literature review. Journal of Gambling Studies. 2018 Mar 05. URL: https://doi.org/10.1007/s10899-018-9763-1 [accessed 2020-05-27]

56. Krkovic K, Clamor A, Lincoln TM. Emotion regulation as a predictor of the endocrine, autonomic, affective, and symptomatic stress response and recovery. Psychoneuroendocrinology 2018 Aug;94:112-120. [doi: 10.1016/j.psyneuen.2018.04.028]

57. Doré BP, Silvers JA, Ochsner KN. Toward a Personalized Science of Emotion Regulation. Social and Personality Psychology Compass 2016 Apr 03;10(4):171-187. [doi: 10.1111/spc3.12240]

58. Batthyány D, Müller KW, Benker F, Wölfling K. Computerspielverhalten: Klinische Merkmale von Abhängigkeit und Missbrauch bei Jugendlichen. Wien Klin Wochenschr 2009 Aug;121(15-16):502-509. [doi: 10.1007/s00508-009-1198-3]

59. Wölfling K, Müller K. Computerspielsucht. In: Batthyány D, Pritz A. editors. Rausch ohne Drogen Substanzgebundene Süchte. New York: Springer; 2009:291-307.

60. Plante CN, Gentile DA, Groves CL, Modlin A, Blanco-Herrera J. Video games as coping mechanisms in the etiology of video game addiction. Psychology of Popular Media Culture 2019 Oct;8(4):385-394. [doi: 10.1037/ppm0000186]

\section{Abbreviations}

BSI: Brief Symptom Inventory

EFA: exploratory factor analysis

GD: gaming disorder

IGD: internet gaming disorder

IGDT-10: 10-Item Internet Gaming Disorder Test

KMO: Kaiser-Meyer-Olkin 
Edited by G Eysenbach; submitted 08.06.20; peer-reviewed by D Schwartz, G Darville; comments to author 01.08.20; revised version received 13.08.20; accepted 16.08.20; published 23.03.21

Please cite as:

Bányai F, Zsila Á, Kökönyei $G$, Griffiths $M D$, Demetrovics Z, Király $O$

The Moderating Role of Coping Mechanisms and Being an e-Sport Player Between Psychiatric Symptoms and Gaming Disorder: Online Survey

JMIR Ment Health 2021;8(3):e21115

URL: https://mental.jmir.org/2021/3/e21115

doi: $\underline{10.2196 / 21115}$

PMID: 33755024

CFanni Bányai, Ágnes Zsila, Gyöngyi Kökönyei, Mark D Griffiths, Zsolt Demetrovics, Orsolya Király. Originally published in JMIR Mental Health (http://mental.jmir.org), 23.03.2021. This is an open-access article distributed under the terms of the Creative Commons Attribution License (https://creativecommons.org/licenses/by/4.0/), which permits unrestricted use, distribution, and reproduction in any medium, provided the original work, first published in JMIR Mental Health, is properly cited. The complete bibliographic information, a link to the original publication on http://mental.jmir.org/, as well as this copyright and license information must be included. 